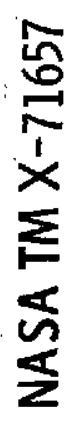

A MULTIPLE THRUSTER ARRAY FOR 30-CM THRUS TERS

by V. K. Rawlin and M. A. Mantenieks

Lewis Research Center

Cleveland, Ohio 44135

TECHNICAL PAPER to be presented at Eleventh Electric Propulsion Conference sponsored American Institute of Aeronautics and Astronautics New Orleans, Louisiana, March 19-21, 1975

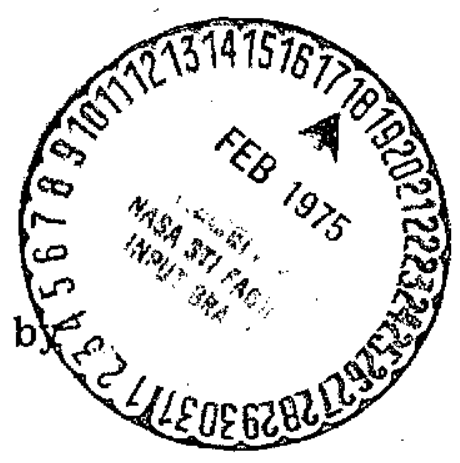

(NASA-TH-X-71657) A MULTIPLE THRUSTER ARRAY FOR $30-\mathrm{cm}$ THRUSTERS (NASA) $13 \mathrm{p}$ HC $\$ 3.25$ 


\title{
A MULTIPLE THRUSTER ARRAY FOR 30-CM THRUSTERS
}

\author{
V. K. Rawlin and M. A. Mantenieks \\ National Aeronautics and Space Administration \\ Lewis Research Center \\ Cleveland, Ohio
}

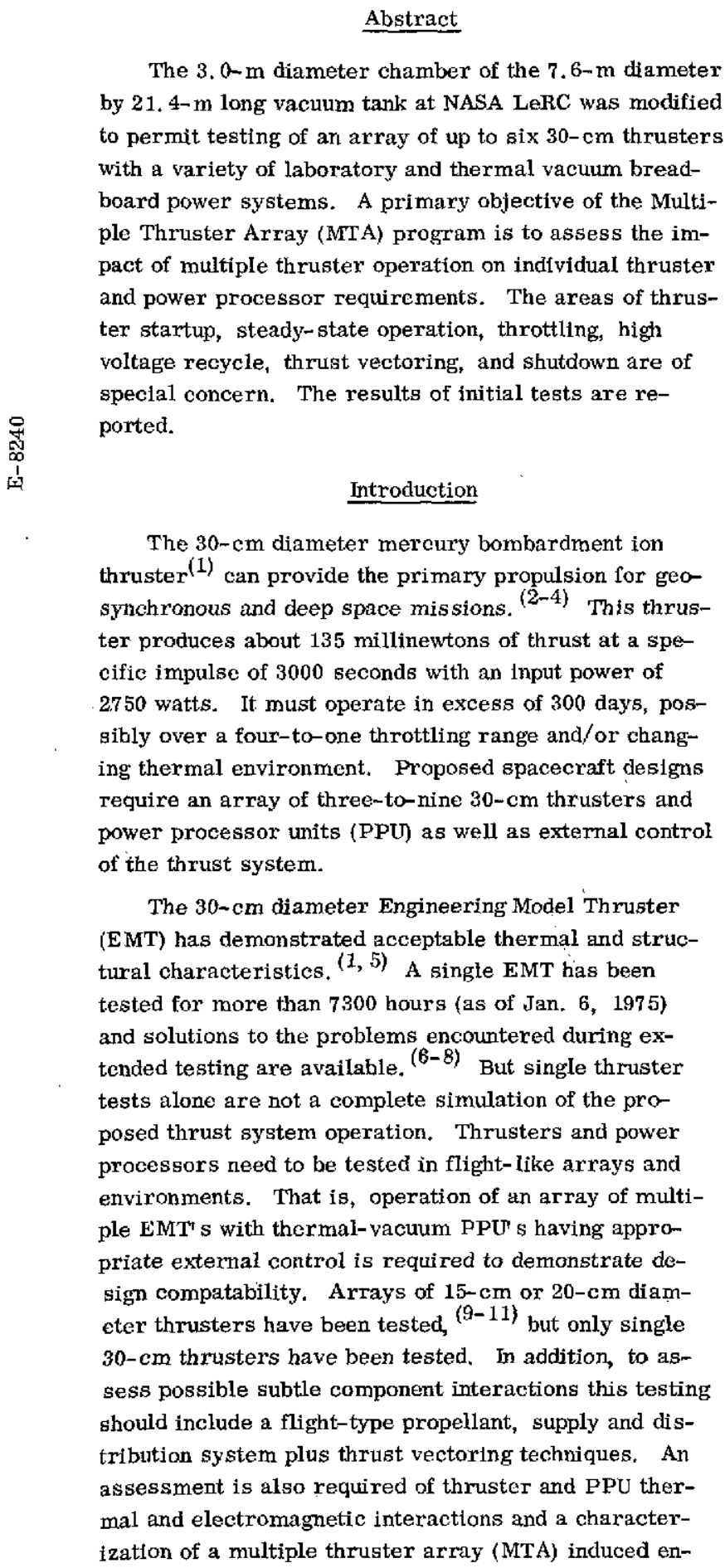

vironment as well as all thruster-spacecraft interactions. To accomplish these goals, a program was generated to test an array of multiple thrusters and power processors. As this program is just beginning experimentally, much of the program description is of possible future work. Work of this type, however, whether performed at LeRC or elsewhere, will be required for any proposed primary electric propulsion mission. This paper discusses that program and the results of initial testing of two preengineering model 30-cm diameter thrusters.

\section{Multiple Thruster Array Program}

The Multiple Thruster Array (MTA) program was designed to demonstrate the propulsion system functions required by a spacecraft with electric thrusters. The experimental model MTA can be continuously updated with the most recent engineering model hardware. Equipment used in the program includes the large vacuum tank facility, MTA frame, thrust vectoring hardware, experimental and engineering model thrusters, laboratory and flight-like propellant supply and distribution systems, laboratory and thermal vacuum power systems, appropriate cabling, a solar array simulator, a digital computer, supporting test equipment and a data acquisition system.

The overall MTA program is comprised of several interrelated programs, the most important of which are listed and described below.

Effects of Multiple Thruster Operation on Thruster/PPU Requirements

There are many ways in which the operation of multiple thrusters may affect the requirements of the hereto-fore individually tested EMT's and PPU's. Four major concerms are: (1) Thruster-power system operation; (2) Beam elflux; (3) Electromagnetic interactions; and (4) Lifetime.

These concerns may also be functions of particulax thruster and power processor designs. Thrusters used for initial tests are pre-engineering model thrusters. As engineering model thrusters are acquired they will be added to the MTA. Several different types of PPU's will be available for MTA tests. For initial tests, a high capacity slow response laboratory-type power system, and a silicon controlled rectifier ( $\mathrm{SCR}$ ) thermal vacuum breadboard (TVBB) PPU were used. An improved SCR TVBB and a transistorized TVBB, which 
have been procured, will be used in future tests. In addition, later generation electrical prototype PPU's will be tested on the MTA.

Thruster-power processor operation. In recent years, operation of individual experimental and eng1neering model $30-\mathrm{cm}$ thrusters has been well documented. $(1,5 ; 12-22)$ These works have been conducted on a component level (cathodes, isolators, vaporizers, discharge chamber geometry, magnetic field strength and shape, and ion extraction systems) and as a complete thruster system (controls, thermal interactions, and plasma fluctuations). These efforts have included operation during startup, steady-state, throttling, and shutdown. It is important to demonstrate that the operation of multiple thrusters in close proximity does not jeopardize the performance developed for single thrusters. Several areas of concern exist.

One concern for example, is whether each thrusterPPU combination should be electrically isolated from the others except for the mercury feedline interconnections. (Thrusters will be inherently coupled, to some degree, by electromagnetic and beam plasma interactions.) If the neutralizer commons of the thrusters were connected, an unbalance of electron emission from the neutralizers could exist, resulting in an overheating of the neutralizer cathode. Also, if one thruster was operating and the booster voltage was applied to the keeper electrode of a nearby neutralizer, electrons from the operating neutralizer could easily Ioad down the keeper voltage of the ather thruster and possibly prevent ignition of that neutralizer. With isolated neutralizer commons, however, if a neutralizer on one thruster failed, it might be desirable to have the ability to connect that thruster common to the common of an adjacent thruster in order to share the operating neutralizer.

A second area of concern is that of the neutralizer vaporizer control loop. Some difficulty has been experienced in obtaining a sultable control logic or keeper voltage-flow rate characteristic for the neutralizer of the $30-\mathrm{cm}$ thruster. (17) The difficulty is complicated by the necessity of control over a 4:1 throttle range of thruster input power. When multiple thrusters are tested, the variety of thruster beam configurations resulting from the number and position of operating thrusters is almost certain to affect individual neutralizer performance.

A third concern is that of the logic required to alleviate an overcurrent condition of the high voltage supplies. Presently, certain precautions such as cathode emission current cutback, discharge voltage set point change, and main vaporizer current reduction are necessary to achieve a recycle which avoids repetitive recycles. (23) This logic may not be adequate for multiple thruster operation.
Beam efflux. To determine the effects of electric propulsion on spacecraft design an effort must be expended to document the efflux from a $30-\mathrm{cm}$ thruster. $(24,25)$ The thruster exhaust not only includes the high energy beam ions which are directed downst ream but also a small number of high energy ions at wide dispersion angles. In addition, small numbers of low energy ions and neutral particles at large angles have also been detected. Generation and final direction of these efflux species depend on the extraction system design and the thruster operating parameters. With multiple thrusters operating, other variables such as the number and position of the thrusters and the throttle level may also affect beam efflux results.

Electromagnetic interactions. Recent studies have been aimed at evaluating the beam and discharge fluctuations of the $30-\mathrm{cm}$ thruster during startup, stcady - state and recycle conditions and their effect on PPU input current, thruster performance, and lifetime. $(22,26)$ These studies should be extended to investigate the operation of multiple thrusters with flight-like PPU' s and the possible impact of operation with a single de input or solar-cell array simulator. The, radiated and conducted, electromagnetic contamination from the thruster array, may also have adverse affects on PPU logic and may require design changes in cabling, shielding, and spacecraft communications systems or experiments.

Lifetime, Extended operation of a $30 \mathrm{~m} \mathrm{~cm}$ thruster, on a component and system level, has been demonstrated, $(8,16,18)$ Operation of multiple thrusters may cause, isolators or cathodes to operate at higher temperatures, neutralizers to receive more direct ion erosion, or increased accelerator grid charge-exchange erosion. In addition, thruster ground screens or spacecraft surfaces may experience sputtering or deposition not observed during single thruster operation. Therefore, extended testing should be conducted with the MTA to determine the effects of multiple thruster operation on the lifetimes of individual thruster components.

\section{Other Effects of Multiple Thruster Operation}

Thrusters and PPU's are only one subsystem of the total thrust system of solar electric propulsion. Interface requi rements between other components of the thrust system must be defined and assessed.

Preliminary results of testing individual experimental and engineering model thrusters to obtain sufficient data to generate a thermal model of a $30-\mathrm{cm}$ thruster have been reported. $(5,21)$ Any thermal model generated for a single thruster should also be expanded to include multiple thruster operation. The MTA will be capable of providing information for that model and useful for defining and evaluating thermal control surfaces. The thermal coupling between thrusters on the MTA and be- 
tween the thrusters and the MTA frame should also be defined for various combinations of thrusters. A variety of requirements from solar heating, thruster and power processor cold survival, or duty cycle are possible due to the numerous mission profiles. The operation of thrusters and PPU's at cold environments ranging from short eclipses of near earth missions to those simulating deep space need to be demonstrated.

Individual thruster performance is usually documented by using separate feedlines to each vaporizer of the thruster. For the MTA, use of in-line valves will allow switching from external reservoirs and flow tubes to internal flight-like propellant tanks. Prototype propellant tanks from the Space Electric Rocket Test (SERT II) program are presently available and two similar bladder-expulsion tanks, each capable of storing $91 \mathrm{~kg}$ of mercury, have been purchased. Several different designs of field joints, propellant lines, valves and, perhaps vacuum flowmeters are being considered.

Interactions may occur between the fields or particle fluxes surrounding operating ion thrusters and the solar cell array required to power the thrust subsystem. Therefore, a program to evaluate the performance of a small panel of solar cells in close proximity to the MTA has been proposed.

Commercial dc power sources, presently being used to simulate a solar array for inverter-type PPU's, are satisfactory for steady-state operation but do not offer, to the PPU, the same source impedance as a solar array would. Plasma fluctuations in the thruster are reflected back to the PPU and may be of sufflcient magnitude to overload a solar array but not a laboratory power source. Interactions between the thruster, PPU and solar array simulator are of great interest. Therefore, several concepts are being pursued to build a solar array simulator which will provide adequate de power to the PPU yet respond to input current demands of the PPU as would a solar array. The basic problem occurs because efficient use of the solar array requires operation near the maximum power point (near the knee of the I-V characteristic) of the solar array. Any transients, such as unfilterable fluctuations or arcs between the thruster grids, may cause momentary demands for more power, which, causes the solar array to be current limited with a corresponding drop in the output voltage. If the output voltage drops below the minimum allowable input voltage of the PPU, the PPU will shut OFF, thus requiring a restart sequence. Present specifications require the current ripple, generated by the PPU on the solar panel line, be less than 1 percent of the average input current. This necessitates a heavy, complicated input filter or a sensor to detect and act upon transients before the solar array does. A solar array simulator to operate a single PPU has been designed and is currently being fabricated.
A $30-\mathrm{cm}$ diameter ion thruster has been operated with a low capacity, fast response $60-\mathrm{Hz}$ laboratory PPU which was controlled by a digital computer. ${ }^{(27)}$ In those tests, the command functions and a computer code format for a spacecraft control system were generated and used to operate that thruster system. An acceptable throttle program was also defined and tested. With the work of Ref. 27 serving as a basis, it is intended that three thrusters will be operated on the MTA using flight-like $\mathrm{PPU}_{\mathrm{S}} \mathrm{a}$ and controlled by a similar laboratory computer. The MTA program goals include the eventual operation of a simulated spacecraft computer located on the MTA frame near the thrusters and PPU $s$.

Thrust vectoring concepts being evaluated for the MTA include a two-axis pivoted gimbal system using two linear actuators, a gimballed platform on which the array of thrusters would be mounted, and a two-axis rotary gimbal system similar to that described in Ref. 28. Thrust vectoring schemes will be evaluated with a 23channel movable probe rake ${ }^{(29)}$ to determine pointing accuracy and beam interactions. The different vectoring schemes will also be judged for operating efficiency in terms of weight, output torque, power required, repeatability, and lifetime.

Thrust vectoring by gimballing thrusters requires flexible feedlines and electrical cables. The size and number of wires as well as types of conductor and insulation are to be addressed in the program. Other areas of concern are the use of a single connector for all high voltage and low voltage wires, requirements for shielding, and proper termination of thruster component power leads.

\section{Apparatus}

\section{Facility}

The MTA tests were conducted in the $3.0-\mathrm{m}$ diameter by $3.0-\mathrm{m}$ long chamber of the 7.6-m diameter by 21.4-m long vacuum tank at Lewis Research Center. ${ }^{(30)}$ The tank has liquid nitrogen cold walls and operates at a pressure of $5 \times 10^{-7}$ torr under load. The test chamber may be isolated from the main vacuum tank by a $3,0-\mathrm{m}$ diameter gate valve. The 3. $0-m$ diameter end cap for the test chamber may be rolled back, as shown in Fig. 1, to permit servicing of the MTA. The test chamber, shown in Fig. 2, also has an independent liquid nitrogen cold wall and separate diffusion pumps to permit vacuum cold-soaking of the MTA. In addition, a surface with resistive heaters and liquid nitrogen cooling lines has been installed to provide a suitable environment for tests of PPU's mounted on the MTA.

Spacecraft Simulator Frame

Figures 1 and 3 show the rectangular magnesium 
alloy spacecraft simulator frame, herein called the MTA frame, suspended from the vacuum chamber end cap by four $2.5-\mathrm{cm}$ thick fiberglass members. The fiberglass members provide electrical and thermal isolation of the frame from the facility. The frame dimensions are 1.9-m long by $2.0-\mathrm{m}$ wide by $1.0-\mathrm{m}$ high. These permit space for a thermal vacuum computer, associated electronics, and an internal propellant supply and distribution system. In addition there are six longitudinal bays to accommodate breadboard power processors. For the initial tests reported here, only individual mercury feedlines and electrical cabling were located in the interior of the MTA frame. An aluminum transition piece, mounted to the MTA frame, supported the gimbal ring and actuators. All openings in the MTA frame were either screened or baffled to exclude tank plasma electrons while permitting outgassing.

\section{Gimbals}

Initial thrust vectoring of each thruster was accomplished using two SERT II prototype linear actuators as shown in Fig. 4. A semicircular ring, mounted through a two-axis pivot to the transition piece was attached to the thruster at the gimbal pad mounts. This concept is similar to one described in Ref. 31. The linear actuators were also attached to the ring at the gimbal pad mounts and to the transition piecc. Each linear actuator was driven by a high speed hysteresis motor through a 4230 to 1 gear reducer which produced $5.25 \mathrm{~cm}$ travel in 14.6 minutes. The thrust vector could be continuously varied vertically or horizontally by $13.5^{\circ}$.

\section{Thrusters}

Three 30-cm diameter thrusters have been assembled for testing on the MTA. For the initial tests only two thrusters were used. They are alined in a horizontal row, as shown in Fig. 3, with the thruster centerlines $25.4 \mathrm{~cm}$ below the facility and MTA centerline. The thrusters are identified as the Left, and Center thrusters when looking upstream, facing the ion extraction systems. The center-to-center thruster spacing is $67 \mathrm{~cm}$. Figure 3 also shows that the neutralizers for the Left and Center thrusters are positioned $+58^{\circ}$ and $-59^{\circ}$, respectively, from vertical. This gives a neutralizer orifice-to-orifice spacing of $25 \mathrm{~cm}$.

The $30-\mathrm{cm}$ thrusters were modified to give performance similar to the " 700 " series, Engineering Model Thruster described in Ref. 5. Major modifications were made to the magnetic field ion optics and cathode and neutralizer assemblies and are described below.

The Left thruster was originally a "300" series ${ }^{(32)}$ thruster that used a single grid insulated optics system. A "400" series ${ }^{(33)}$ cathode-isolator-vaporizer assembly with a shortened baffle mount and cathode pole piece was installed. The original axjal and radial magnets were replaced with solenoid electromagnets in order to produce a magnetic field with variable shape and strength. The ion opties system for all three thrusters were sets of dished grids, $(12,13)$ with the dish direction downstream. The dimensions of each grid set are given in Table I.

The Center and Right thrusters were originally " 400 " series thrusters ${ }^{(33)}$ having flat two-grid ion optics. The cathode-isolator-vaporizer assembly of each thruster was replaced with a "700" series, "separated" cathode and isolator-vaporizer, assemblies. ${ }^{(5)}$ The magnetic field strength was increased to EMT levels ${ }^{(5)}$ by adding an appropriate number of axial and radial permanent magnets.

The neutralizer assemblies for all three thrusters consisted of a $0.64-\mathrm{cm}$ diameter vaporizer connected with a compression fitting to a $0.64-\mathrm{cm}$ diameter neutralizer cathode having a $0.038-\mathrm{cm}$ diameter, $0.152-\mathrm{cm}$ long arifice. The neutralizer keeper electrode was a 0.64-cm diameter loop of $0.15-\mathrm{cm}$ diameter tantalum wire. The position of each neutralizer orifice with respect to the nearest hole in the accelerator grid was $8.9-\mathrm{cm}$ radially outward and $8.9-\mathrm{cm}$ downstream.

\section{Propellant Feed System}

A separate mercury feedline for each vaporizer was used for initial testing in order to monitor the individual flow rates. Each $0.15-\mathrm{cm}$ diameter stainless steel tube, between the thruster and the MTA frame, had a two and one-half turn, $10-\mathrm{cm}$ diameter coil. This coll provided the feedline flexibility required during thrust vectoring operations, All of the lines were covered with an 1rradiated polyolefin heat-shrinkable tubing to insulate the potential of the feedlines from the tank plasma. The feedline isolation was maintained at the vacuum feedthrough, the individual mercury reservoirs, and the preciston bore glass tubes. The reservoirs were approximately $80 \mathrm{~cm}$ above the level of the vaporizers, giving a 2-atmosphere pressure head during operation. Each mexcury column was calibrated by weighing 10 sample heights of mercury and calculating the constant for a given number of equivalent milliamperes per centimeter per minute of mercury displacement.

\section{Power Systems}

The power system for the Left thruster consisted of 14, 60 hertz, laboratory power supplies. The screen and accelerator high-voltage supplies were a high capacity, three phase, full wave bridge rectifier design. The discharge, magnetic baffle, electromagnets and two keeper supplies were full wave, single phase rectified de sources. The six resistive heaters were powered with alternating current. 
The Center thruster was powered by a thermal vacuum breadboard (TVBB) PPU which is described in Refs. 34 and 35 , and 1 s shown in Fig. 5. This power processor utilizes a sllicon controlled rectifier series resonant circuit to invert the nominal 300 volt de input power. All individual thruster power supply outputs are de and current limited. The overall dimensions are $145-$ by $66-$ by 13.6- $\mathrm{cm}$ high.

Table II lists the maximum and nominal output for each power supply of the laboratory system and the TVBB. Also listed are the open circuit voltages for the discharge and both keeper supplies, Both power systems have proportional control loops for the main, cathode, and neutralizer vaporizer power supplies to maintain desired valucs of beam current, discharge voltage and neutralizer keeper voltage, respectively.

Both power systems are capable of unattended operation. Meter relays were used for the laboratory supplies to monitor critical thruster parameters and provide automatic system shut down. The individual power supplies of the TVBB PPU were all current limited at values which could not damage the thruster. Also, logic internal to the PPU shuts OFF both high voltage supplies if 10 high voltage recycles occur within 1 minute. Circuitry was provided to shut OFF the PPU if the input current exceeded the normal operating value or if the input voltage fell below 180 volts.

Both thrusters and their power systems were isolated from each other, the MTA frame, and the facility ground. This requires that the neutralizer emission current be equal to the ion beam current for each thruster and that the neutralizers operate without a bia voltage. The neutralizer common potential was allowed to float (negative) with respect to facility ground. The potential was limited to a value of 60 volts by a Zener diode clamping system.

One portion of thruster operation which has presented difficulty in the past has been the high-voltage recycle sequence required duxing an overcurrent of elther the screen or accelerator high voltage supplies. $(23,36,37)$ As many techniques exist for this sequence as there are different power systems and thrusters. Figure 6 shows the high voltage recycle sequence for the MTA power systems. The specific times presented were adequate for the thruster-power system combinations used, but are not necessarily the shortest or optimum values.

The laboratory power system had positive and negative high voltage trip currents of 3.5 and $0.5 \mathrm{~A}$, respectively. An overload of either supply would cause the output of both supplies to be shorted and remain shorted for 3 seconds. During the OFF time the positive and negative high voltage setpoints were reduced by ramping down the motor-driven variac primary voltages. In addition, there was no eutback of the discharge current and the main vaporizer current vent its maximum value during the absence of ion beam current. At the end of the 3-second OFF period, the high voltage output shorts were removed, then the voltages and currents increased to their previous steady-state values. The total time required to return to steady-state condition was about 6 seconds.

The SCI TVBB PPU screen and accelerator high voltage supply outputs were current limited at 2.2 and $0.2 \mathrm{~A}$, respectively. Both high voltage outputs obtained their power from a single SCR series resonant inverter. When an overcurrent condition occurred (i. e., accelerator current greater than $0,10 \mathrm{~A}$ for $0,1 \mathrm{sec}$ ) which was not interrupted by the current limiting feature of the supply, the outputs were artificially interrupted by adjusting the control logic for the SCR series inverter to produce no output. This interruption lasted for 0,66 second, during which time the discharge current was reduced to a much lower level and the main vaporizer current was set to zero. When the high-voltage supply was turned $O N$ again and the output voltage and currents were reestablished, the discharge current was reset to its RUN condition (after $1.4 \mathrm{sec}$ ) and the main vaporizer current was released from zero (after $3.5 \mathrm{sec}$ ). The total time for the TVBB to reach steady-state conditions was about 20 seconds.

The power leads from each power system to the corresponding thruster are presently bundles of individual stranded, silver-coated, all polymide insulated wire (MIL-W-8131/1), All wires are number 16 AWG with the exception of leads carrying the discharge current which are number $12 \mathrm{AWG}$.

\section{Data Acquisition}

Most thruster voltages and currents for the Left thruster were monitored through the use of direct current transducers for high voltage isolation and read out on 2 percent taut-band microammeters. The ion beam current and discharge voltage and current were monitored on digital voltmeters. Thruster parameters of the Center thruster were measured at the TVBB output by using $0.1 \mathrm{ohm}$ shunts and 10 to 1 voltage dividers to generate the input signals for two floating digital voltmeters. Separate potential leads were used to monitor the discharge voltage of each thruster.

Thruster parameters were recorded on strip charts during unattended and extended periods of operation.

\section{Procedure}

Thruster START consisted of PREHEAT, IGNITION, and HEAT phases as described in Ref. 36. The length of each phase used was arbitrary and no attempts were made to minimize them. In general, a thruster was 
started by preheating the cathode tip heater, neutralizer tip heater and isolator heater(s). After approximately 30 minutes the cathode and neutralizer vaporizers, cathode and neutralizer keepers and main discharge supplies were turned $O N$. With sufficient thermionic emission from the oxide-coated cathode inserts and adequate mereury vapor flow, the keeper discharges would ignite within 5 minutes. The cathode discharge then coupled to the main anode and provided additional heating of thruster components for approximately 10 more minutes. Main vaporizer current was then applied to increase the plasma density to a level where an ion beam could be extracted without quenching the discharge. Extraction voltage was applied to the thruster approximately 1 hour after the start of preheat.

While both thrusters were operated at full thrust (2.0 A beam current) the ion beams were vectored to the extremes of the gimbal actuators. The thrusters were individually and then simultaneously throttled from full input power to approximately one-fourth input power. At all steady-state thruster operating conditions, the extraction voltages to each thruster were intentionally recycled to observe the effects upon the other thruster. Each thruster was then turned completely OFF with the other thruster operating to detect any interactions.

\section{Results of Initial MTA Tests}

Two pre-engineering model $30-\mathrm{cm}$ diameter ion thrusters have been tested with two different power systems. One thruster had electromagnets and was operated with high capacity, laboratory-type, power supplies. The other thruster utilized permanent magnets and was powered by an external SCR TVBB PPU. Both thruster neutralizer commons and feed systems were electrically isolated from facility ground and each other. However, electrical interactions due to coupling of the beam and/or neutralizer plasmas were expected and found to exist. To assess those interactions during two thruster operations, the thruster floating potentials, neutralizer keeper potentials, and accelerator impingement currents were observed. These interactions are described below for each phase of the thruster operating sequence.

\section{Thruster Start}

The three different combinations of starting two thrusters were evaluated, Each thruster was started at least once with the other thruster operating at full beam current of $2 \mathrm{~A}$ and then both thrusters were started at nearly the same time and brought to a beam current of 2.0 A. No major problems were encountered in starting elther thruster. The only interactions observed were in the accelerator impingement current, the thruster floating potential, and the neutralizer keeper potentlal. The accelerator impingement current of an operating thrus- ter increased by 10 to 20 percent when the other thruster was started and its beam raised to full power. The increase was probably due to charge-exchange ions from the second thruster falling to the accelerator of the first thruster. This increase for the center thruster may double when the third thruster is operated. Normal impingement currents for these tests and other thrusters operated with dished grids is only one-fourth of 1 percent of the beam current so even a doubling of the impingement current level should not impair anticipated accelerator grid lifetime. The problem which may be of more concern is that of increased sputtered efflux from the accelerator grid.

The magnitude of the floating potential of an operating thruster decreased approximately 1 volt whenever a beam was extracted from the other thruster. The opposite was true for the MTA frame floating potential. Typical thruster and MTA frame floating potentials were -12 and -7 volts, respectively. The neutralizer keeper potential of an operating thruster decreased by $1 / 2$ to 1 volt when the beam was extracted from the other thruster. The neutrallzer vaporizer control logic then reduced the neutralizer propellant flow to bring the keeper voltage back to the setpoint. The change in flow was not measured but, from vaporizer temperature indications, it is expected to be small. The level of this interaction may be altered by the use of engineering model hardware or by repositioning the neutralizer.

\section{Hìgh Voltage Recycles}

The data presented below were obtained from strip chart recorders. With both thrusters operating, an overcurrent of sufficient magnitude of either the screen or accelerator supply would result in both supplies of that power system being turned OFF momentarlly. During that time the neutralizer keeper potential for the recycling thruster rose to about two times its normal value and the magnitude of the thruster floating potential decreased to about one-third its normal value. Several parameters of the operating thruster varied to a lesser degree during the recycle. The accelerator impingement current increased about 10 percent. The neutralizer keeper voltage and thruster floating potential both increased, about 1 volt, to the normal values of single thruster operation. All parameters quickly returned to normal two-thruster values when the recycle sequence was completed.

\section{Thrust Vectoring}

When both thrusters were operating at full power the gimbal actuators were energized to their limits. The thruster beams were moved away from each other and then toward each other so they overlapped. Parameter variations during thruster recycle were identical to 
those described above for all gimbal actuator configurations. The only thruster parameter which showed a significant variation was the accelerator impingement current which increased a maximum of 8 percent on each thruster as the lon beams were vectored toward each other. Neutralizer keeper and thruster floating potentials remained unchanged within 0.2 volt.

\section{Throttling}

To investigate the effects of throttling both thrusters were operated at $2 \mathrm{~A}$ and then one thruster was throttied to lower beam currents. Figure 7 shows the variation of the accelerator impingement currents for both thrusters as the beam current of the center thruster was decreased. The changes in the accelerator currents are approximately proportional to the beam current of the throttled thruster. All other parameters during steady-state and recycle conditions were unchanged during the throttle procedure. When one beam current reached zero and the corresponding high voltages were turned OFF; the neutralizer keeper and thruster floating potentials of the other thruster returned to values for single thruster operation.

\section{Concluding Remarks}

The 30-cm diameter mercury ion thruster has reached a high level of development. But single thruster tests alone are not a complete simulation of the proposed thrust subsystem operation. Therefore, the 3.0-m diameter chamber of the 7.6-m diameter by $21.4-\mathrm{m}$ long vacuum tank at NASA LeRC was modified to permit testing of an array of up to six $30-\mathrm{cm}$ diameter thrusters with a variety of laboratory and thermal vacuum breadboard power systems. The primary objective of the Multiple Thruster Axray program is to assess the impact of multiple thruster operation on individual thruster and power processor requirements. Four major areas of concern are, thruster/power processor operation, ion beam efflux, electromagnetic Interactions, and lifetime. These areas of concern apply to thruster/power procesw sor operation during startup, steady-state, throttling, high-voltage recycle, thrust vectoring, and shutdown.

Two pre-engineering model $30-\mathrm{cm}$ thrusters, in close proximity, have been tested with two different power systems. An electromagnet thruster was operated with high capacity laboratory type power supplies while a permanent magnet thruster was operated with a silicon controlled rectifler thermal vacuum breadboard power processor. Operation was observed during staxtup, run, recycle, thrust vectored and throttled conditions. Interactions noted were primarily in the accelerator impingement currents, neutralizer keeper voltages and the thruster floating voltages and are listed below.
1. During the startup of the second thruster, the accelerator impingement current of the first thruster increased by 10 to 20 percent. The neutralizer keeper potential of the operating thruster decreased by $1 / 2$ to 1 volt when an ion beam was extracted from the other thruster. This, in turn, caused a shift of the neutralizer keeper voltage-mereury flow rate characteristic curve to lower flow rates. The thruster floating potential decreased approximately 1 volt in magnitude when the other thruster was turmed ON. These effects were probably due to the increase in the local plasma density.

2. The high voltage recycle of either power processor includes an interruption of the ion beam. There were no noticable differences in the recycle of either power system between single or multiple thruster operation. But, during multiple thruster operation, when one thruster recycled, the three thruster parameters. mentioned above, did fluctuate momentarily.

3. While both thrusters were operating at full power, each thrust vector was varied vertically and then horizontally by $13.5^{\circ}$. The maximum variation of the accelerator impingement current of each thruster was 8 percent. Neutralizer keeper and thruster floating potentials remained unchanged within 0.2 volt.

4. During multiple thruster operation, one thruster was operated at full power while the beam current of the other thruster was throttled from $2 \mathrm{~A}$ to lower values. The changes in accelerator impingement current for each thruster were proportional to the beam current of the throttled thruster. The neutralizer keeper and thruster floating potentials were again nearly unchanged.

Initial operation of multiple thrusters is quite encouraging since the only obvious interactions are those listed above. Additional testing of three thrusters (eventually EMT' $\mathrm{s}$ ) with both SCR and transistorized TVBB's is being conducted to identify and evaluate the more subtle changes in single thruster performance when operated in the Multiple Thruster Array.

\section{References}

1. Sovey, J. S. and King," H. J., "Status of 30Centimeter Mercury Ion Thruster Development," AIAA Paper 74-1164, San Diego, Calif., 1974.

2. Gilbert, J, and Guttman, C. H., "The Evolution of the SEP Stage/SEIS/ Concept, " AIAA Paper 73-1122, Lake Tahoe, Nev, , 1973.

3. Masek, T. D., Richardson, E. H. and Watkins, C. L., "Solar Electric Propulsion Stage Design, " AIAA Paper 73-1124, Lake Tahoe, Nev., 1973.

4. Duxbury, J. H., "A Solar-Electric Spacecraft for the Enke Slow Flyby Mission, " AIAA Paper 73-1126, Lake Tahoe, Nev., 1973. 
5. Poeschel, R. L., King, H. J. and Schnelker, D. E., "An Engineering Model $30 \mathrm{~cm}$ Ion Thrugter, " ALAA Paper 73-1084, Lake Tahoe, Nev., 1973.

6. Mantenieks, M. A. and Rawlin, V. K., "Studies of Internal Sputtering on a 30-Centimeter Thruster, " AIAA Paper 75-400, New Orleans, La., 1975.

7. Poeschel, R. L. and Vahrenkamp, R. P., "Performance Mapping of a 30-Centimeter Engineering Model Thruster, " ALAA Paper 75-342, New Orleans, La., 1975.

8. Collett, C. R., "A 7700-Hour Endurance Test of a 30-Centimeter Kaufman Thruster, " AIAA Paper 75-366, New Orleans, La., 1975.

9. Pawlik, E. V., "An Experimental Evaluation of Array of Three Electron Bombardment Ion Thrusters," TN D-2597, 1965, NASA.

10. Pawlik, E. V. and Reader, P. D., "Accelerator Grid Durability Tests of Mercury ElectronBombardment Ion Thrusters, "TN D-4054, 1967.

11. Masek, T. D., "Solar Electric Propulsion Thrust Subsystem Development, " JPL-TR-32-1579, March 1973. Jet Propulsion Laboratory, Pasadena, Calif.; also CR-131360, 1973, NASA.

12. Rawlin, V. K., "Studies of Dished Accelerator Grids for 30-cm Ion Thrusters, " AIAA Paper 73-1086, Lake Tahoe, Nev., 1973.

13. Rawlin, V. K., "Performance of 30-cm Ion Thrusters with Dished Accelerator Grids," AIAA Paper 73-1053, Lake Tahoe, Nev, , 1973.

14. Vahrenkamp, R. P., "Measurement of Doublo Charged Ions in the Beam of a 30-cm Mercury Bombardment Thruster, "ALAA Paper 73-1057, Lake Tahoe, Nev., 1973.

15. Danilowicz, R. L., Rawlin, V. K., Banks, B. A. and Wintucky, E. G., "Measurement of Beam Divergence of 30-Centimeter Dished Grids, "AIAA Paper 73-1051, Lake Tahoe, Nev., 1973.

16. Mirtich, M. J., "Investigation of Hollow Cathode Performance for 30-cm Thrusters, " AIAA Paper 73-1138, Lake Tahoe, Nev., 1973.

17. Bechtel, R. T., "A Hollow Cathode Neutralizer for a 30-cm Diameter Bombardment Thruster," AIAA Paper 73-1052, Lake Tahoe, Nev, 1973.

18. Mantenieks, M. A., "Investigation of Mercury Thruster Isolators," AIAA Paper 73-1088, Lake Tahoe, Nev, , 1973.

19. Kerslake, W. R., "Design and Test of PorousTumgsten Mercury Vaporizers, " AIAA Paper 72-484, Bethesda, Md., 1972.
20. Poeschel, R. L., "The Variable Magnetic Baffle as a Control Device for Kaufman Thrusters, "AIAA Paper 72-488, Bethesda, Md, 1972.

21. Mirtich, M. I., "The Effect of Exposure to $\mathrm{LN}_{2}$ Temperatures and 2.5 Suns Solar Radiation on 30-Centimeter Ion Thruster Performance, "AIAA Paper 75-343, New Orleans, La., 1975.

22. Serafini, J. S., Mantenieks, M. A, and Rawlin, V. K., "Dynamic Characteristics of a 30Centimeter Mercury Ion Thruster, AIAA Paper 75-345, New Orleans, La., 1975.

23. Terdan, F, F. and Bechtel, R. T., "Control of a $30 \mathrm{~cm}$ Diameter Mercury Bombardment Thruster," AIAA Paper 73-1079, Lake Tahoe, Nev., 1973.

24. Weigand, A. J. and Mirtich, M. J., "Measurement of Sputtered Efflux from 5-, 8-, and 30Centimeter-Diameter $\mathrm{Hg}$ Ion Thrusters, " AIAA Paper 75-358, New Orleans, La., 1975.

25. Ward, J. W. and Hahrenkamp, R, P., "Characterization of Ion and Neutral Efflux from a $30-$ Centimeter Mercury Ion Thruster, "AIAA Paper 75-357, New Orleans, La., 1975.

26. Serafini, J. S. and Terdan, F. F., "Plasma Fluctuations in a Kaufman Thruster, "AIAA Paper 73-1056, Lake Tahoe, Nev., 1973.

27. Low, C. A., "Digital Computer Control of a 30Centimeter Mercury Ion Thruster, " AIAA Paper 75-380, New Orleans, La., 1975.

28. Marsh, E. L., "Multiple Gimballing of Thrusters for Thrust Vector Control and Thrust Vector Reorienting of Solar Electric Spacecraft, " ALAA Paper 73-1116, Lake Tahoe, Nev., 1973.

29. Banks, B. A., Rawlin, V. K., Weigand, A. J. and Walker, J., "Direct Thrust Measurement of a 30-Centimeter Ion Thruster, " AIAA Paper 75-340, New Orleans, La., 1975.

30. Finke, R. C., Holmes, A. D, and Keller, T. A., "Space Environment Facility for Electric Propulsion Systems Research," TN D-2774, 1965, NASA.

31. "8-Centimeter Mercury Ion Thruster System Technology," AIAA Paper 74-1116, San Diego, Calif., 1974.

32. King, H. J. and Poeschel, R. I., "Low Specific Impulse Ion Engine, " Feb. 1970, Hughes Research Labs., Malibu, Calif., CR-72677, 1970, NASA.

33. "Low Voltage $30 \mathrm{~cm}$ Ion Thruster, " Feb. 1972, Hughes Research Labs., Malibu, Calif., CR-120919, 1972, NASA. 
34. Biess, J. J., Schoenfeld, A. D., Goldin, D. S. and Shank, J. H., "Interface Røquirements for Electric Propulsion Power Processing Equipment, " AIAA Paper 73-1108, Lake Tahoe, Nev., 1973.

35. Biess, J. J., Inouye, L. Y., Schoenfeld, A. D., and Shank, J. H., "Thyristor Power Processor for the 30-Centimeter Mercury Electric Propulsion Engine," ALAA Paper 75-433, Now Orleans, La, , 1975.
36. Bechtel, R. T., "Control Logic for a 30-CentimeterD1ameter Ion Thruster, " AIAA Paper 75-378, New Orleans, Li.., 1975.

Table I Dished grid geometries

\begin{tabular}{|c|c|c|}
\hline \multirow[t]{2}{*}{ Grid parameters } & \multicolumn{2}{|c|}{ Grid dimensions } \\
\hline & Left thruster & Center and right thrusters \\
\hline Diameter of perforated region, $\mathrm{cm}$ & 28.6 & 28.6 \\
\hline Dish diameter, $\mathrm{cm}$ & 30,0 & 30.0 \\
\hline Dish depth, $\mathrm{cm}$ & 2.3 & 2.3 \\
\hline Hole center-to-centor spacing, $\mathrm{cm}$ & 0.234 & 0.221 \\
\hline Hole shape & Hexagonal & Cireular \\
\hline Screen grid: & & \\
\hline Hole diameter, cm & 0.203 (across flats) & 0.191 \\
\hline Open area fraction & 0.77 & 0.67 \\
\hline Thickness, cm & 0.038 & 0.038 \\
\hline Compensation $^{\mathrm{a}}$ & 0.003 & 0.004 \\
\hline Accelerator grid: & & \\
\hline Hale diameter, $\mathrm{cm}$ & 0.124 (across flats) & 0.152 \\
\hline Open area fraction & 0.28 & 0.43 \\
\hline Thickness, cm & 0,038 & 0.051 \\
\hline
\end{tabular}

${ }^{\mathrm{a}}$ Reduction ratio of screen grid dimensions to compensate for beam divergence due to grid shape and hole misalinement.

Table II Power system supply outputs

\begin{tabular}{|c|c|c|c|c|c|c|}
\hline \multirow[t]{3}{*}{ Power supply } & \multicolumn{4}{|c|}{ Maximum } & \multicolumn{2}{|c|}{ Nominal } \\
\hline & \multicolumn{2}{|c|}{ Laboratory } & \multicolumn{2}{|c|}{$\operatorname{TVBB}^{a}$} & & \\
\hline & $\mathrm{v}$ & A & $\mathrm{v}$ & A & $\mathrm{v}$ & A \\
\hline Main vaporizer & 20 & 3 & 10 & 2 & 6 & 1.0 \\
\hline Cathode vaporizer & 15 & 5 & 10 & 2 & 3 & 1.0 \\
\hline Cathode heater ${ }^{b}$ & 15 & 10 & 15 & 6 & 15 & 4.5 \\
\hline Isolator heaters $^{\mathrm{b}}$ & 20 & 5 & 10 & 4 & 10 & 4 \\
\hline Ncutralizer heater ${ }^{b}$ & 15 & 10 & 10 & 5 & 15 & 4.5 \\
\hline Neutralizer vaporizer & 15 & 5 & 10 & 2 & 3 & 1.0 \\
\hline Neutralizer keeper & 30 & 3.0 & 20 & 3 & 15 & 2.0 \\
\hline Boost & 425 & .020 & $>1000$ & .020 & & \\
\hline Cathode keeper & 30 & 1.0 & 60 & 1 & 7 & .5 \\
\hline Boost & 425 & .020 & $>1000$ & .020 & & \\
\hline Discharge & 70 & 30 & 60 & 14 & 37 & 12 \\
\hline Boost & 90 & .020 & $>65$ & .020 & & \\
\hline Accelerator & 1500 & .5 & 500 & .2 & 500 & .004 \\
\hline Streen & 1500 & 3.5 & 1500 & 2.2 & 1100 & 2.0 \\
\hline Magnetic baffle & 10 & 20 & 2 & 5 & 1 & 5 \\
\hline
\end{tabular}

$a_{\text {Thermal vacuum breadboard, }}(34,35)$

btart only. 


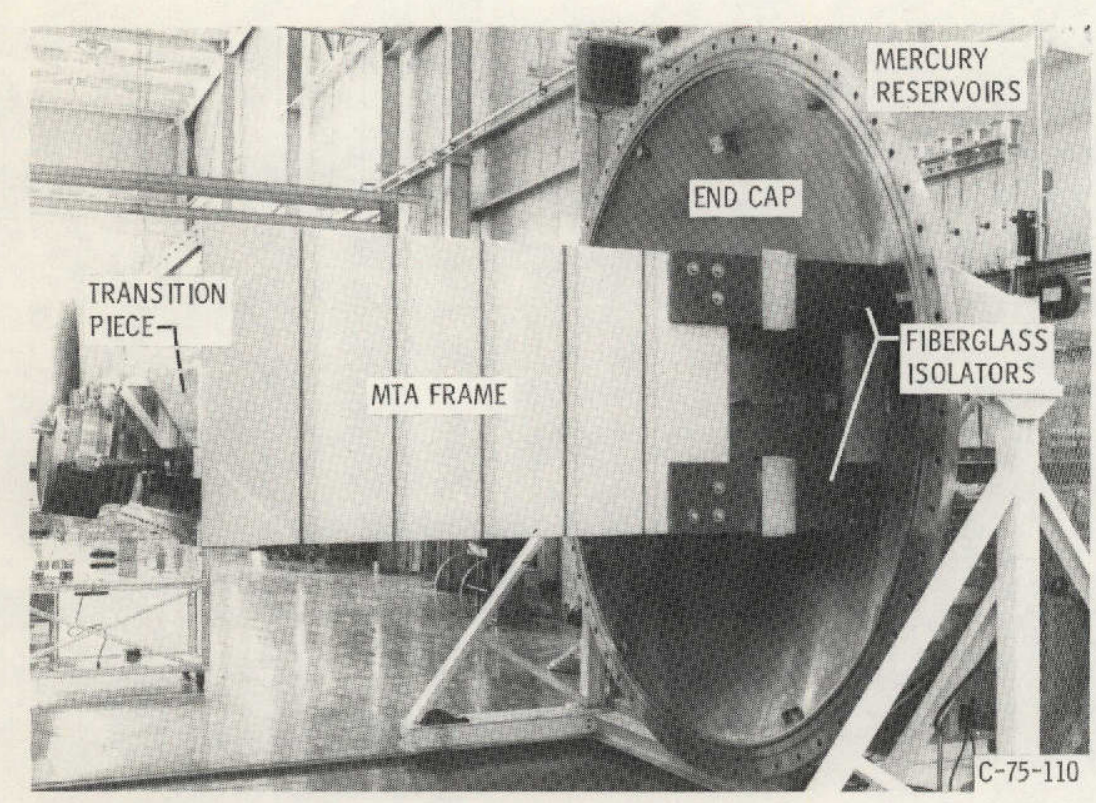

Figure l. - Test chamber end cap and MTA frame.

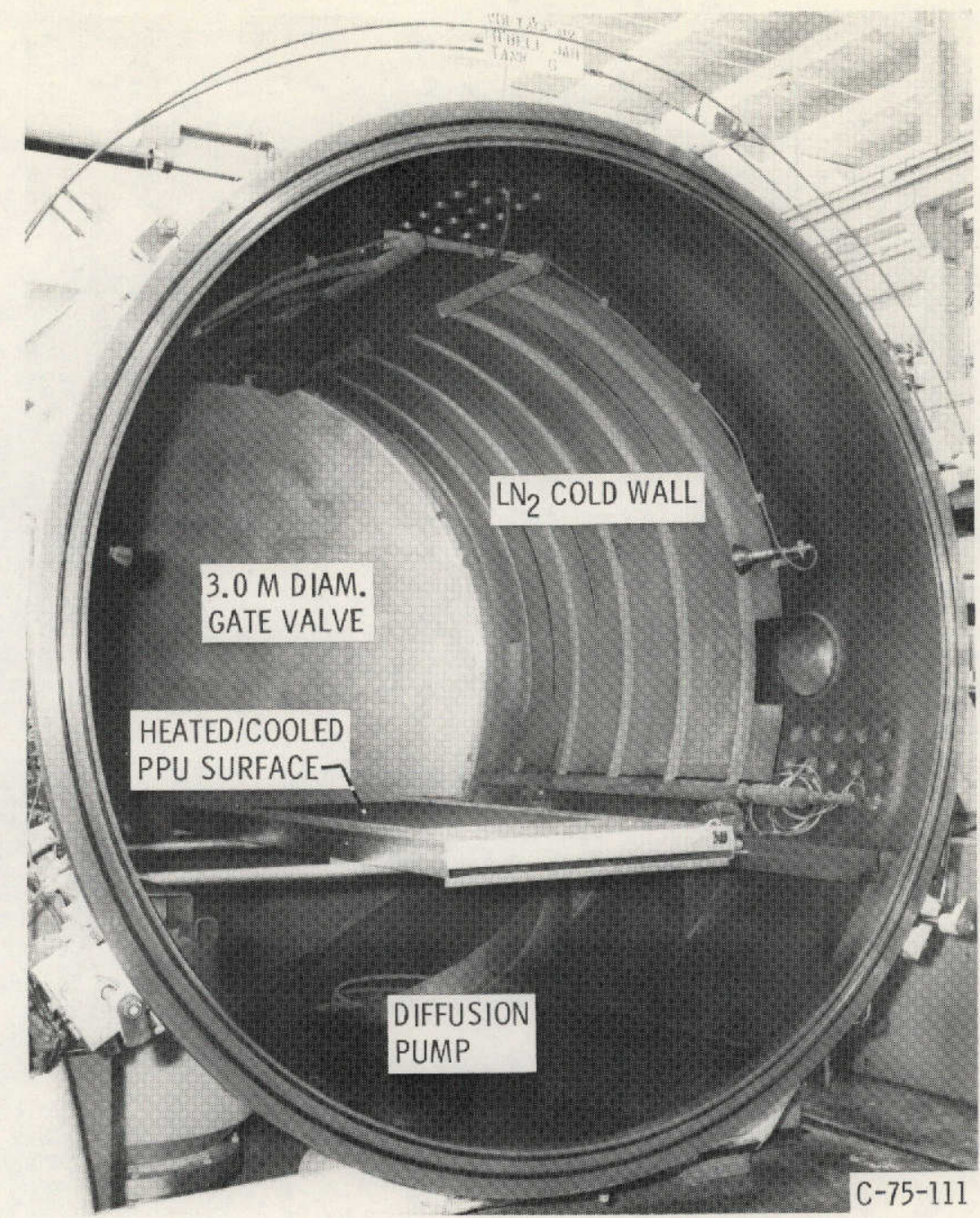

Figure 2. - MTA test chamber. 


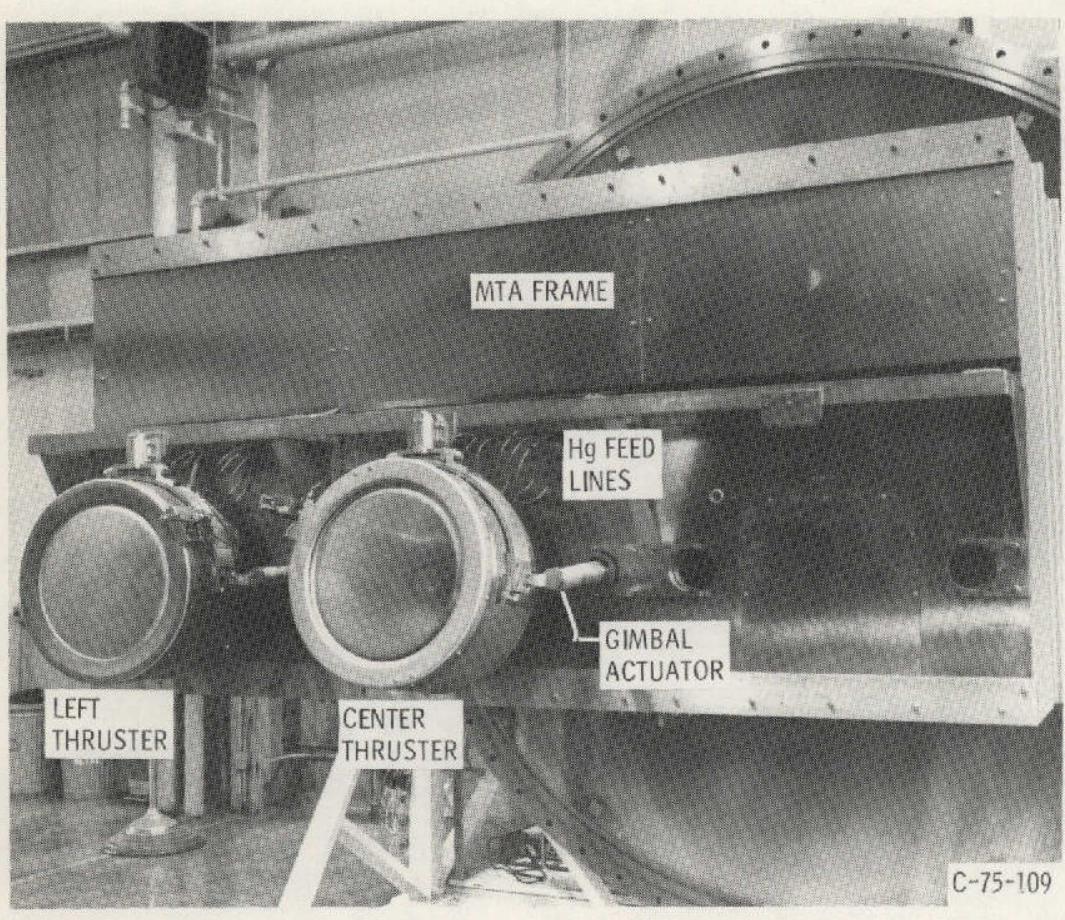

Figure 3. - MTA frame and thrusters.

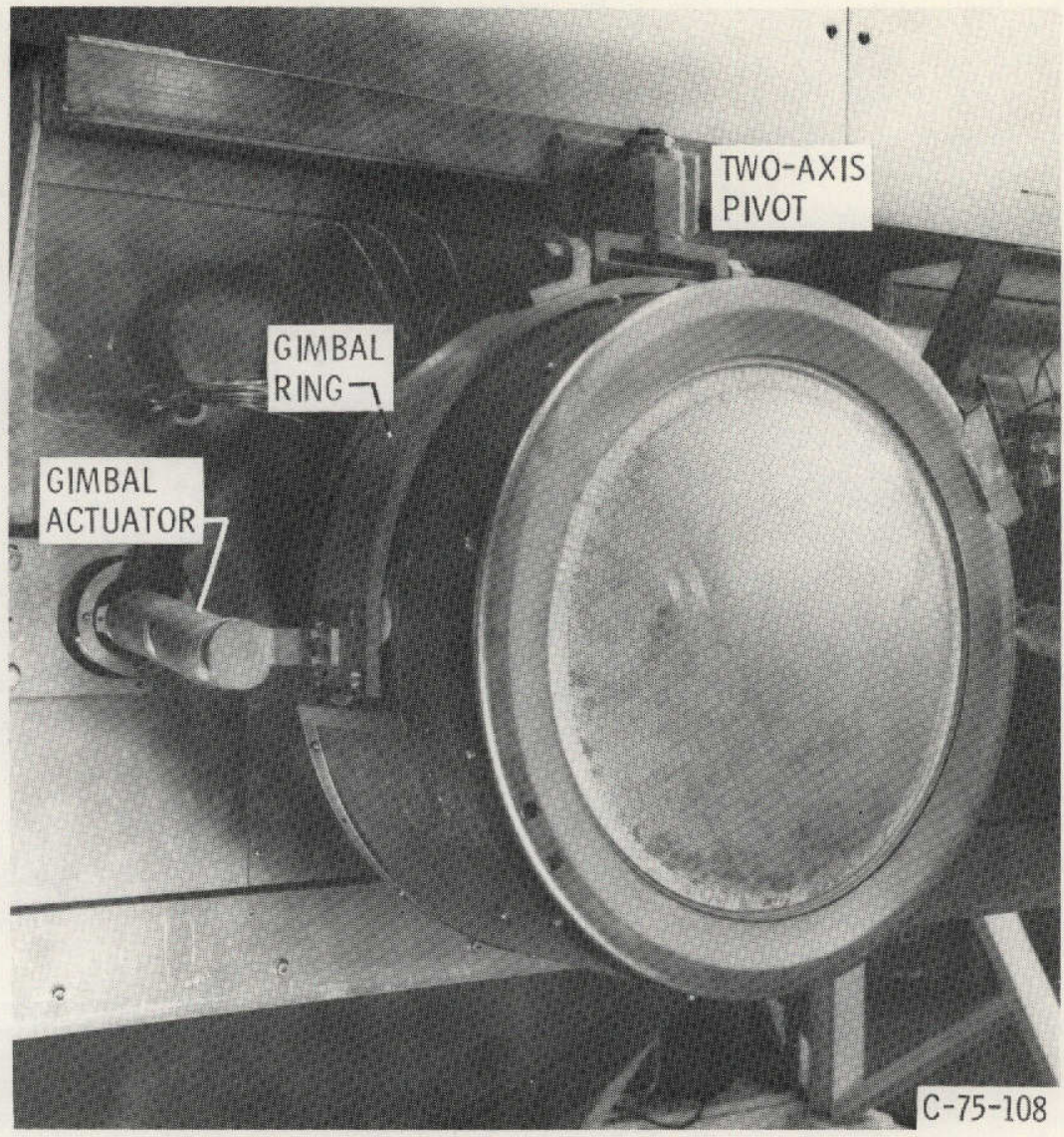

Figure 4. - Gimbal mount and actuators. 


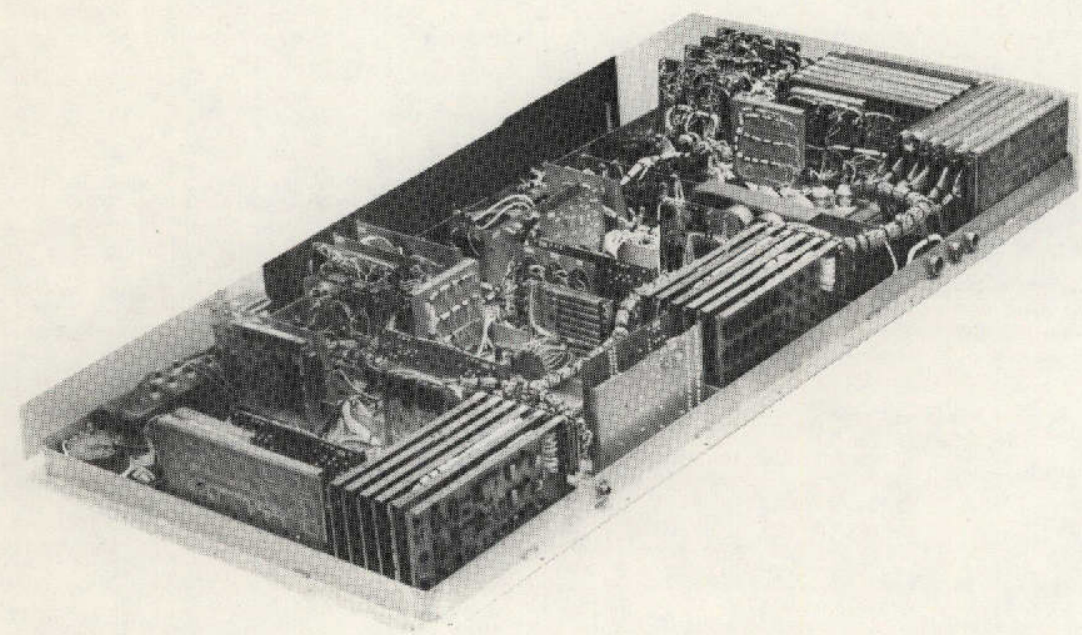

Figure 5. - Silicon controlled rectifier thermal vacuum breadboard power processor.

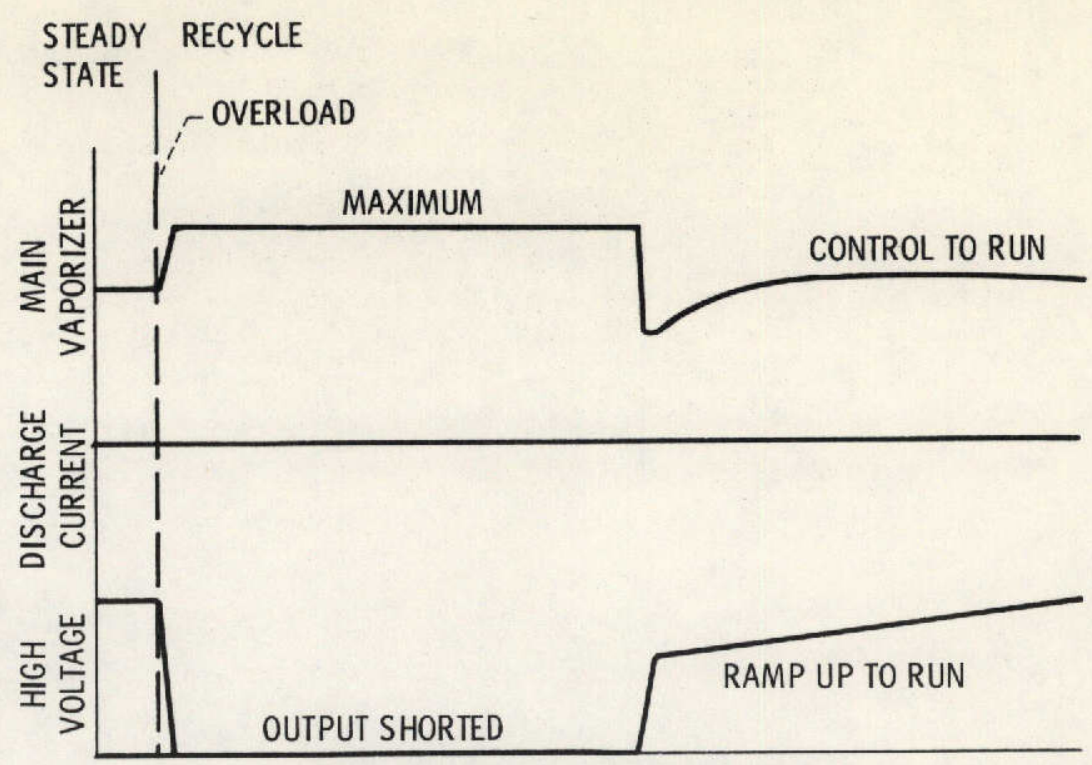

(a) LABORATORY POWER SYSTEM.

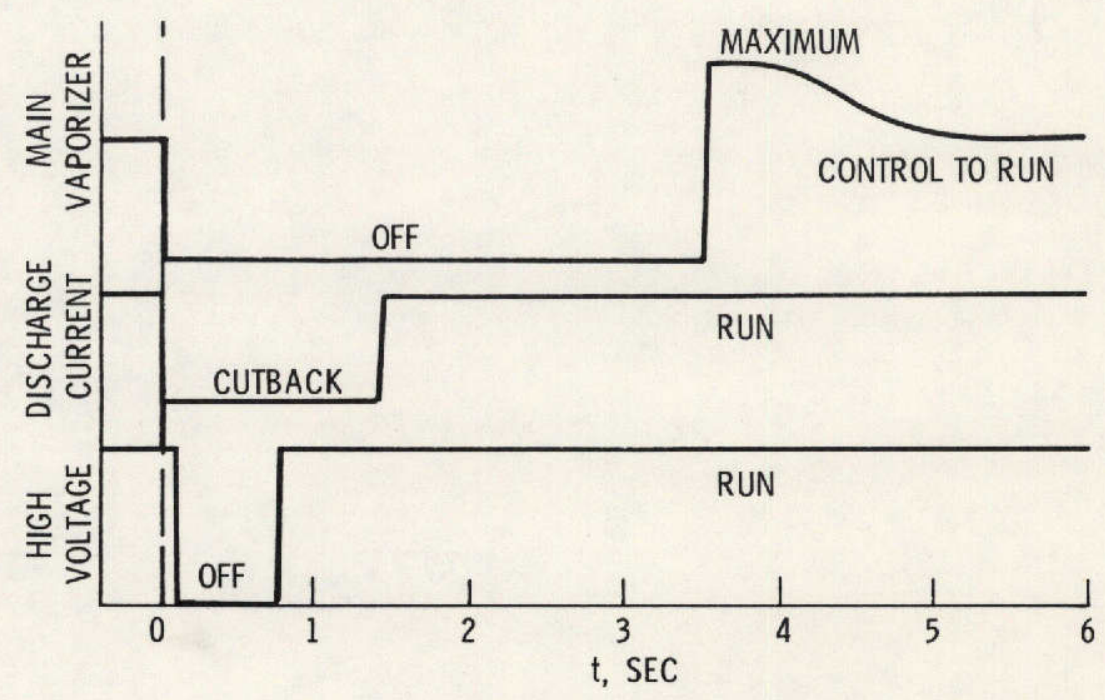

(b) SCR TVBB PPU.

Figure 6. - High voltage recycle sequence for the two power systems used in MTA tests. 


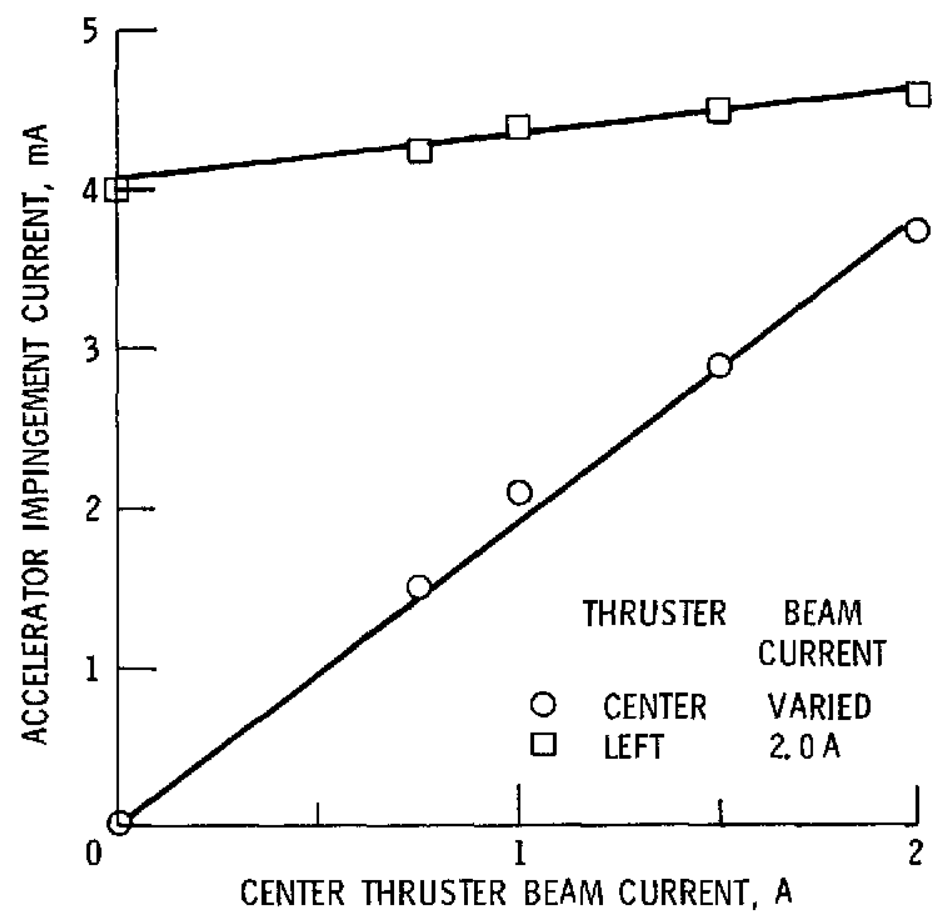

Figure 7. - Variation of the accelerator impingement current of both MTA thrusters as a function the beam current of one thruster. 